OPINION ARTICLE

\title{
Physical Activity in the Prevention of Abdominal Obesity: Type, Duration and Intensity
}

\author{
${ }^{1}$ Departamento de Educação Física, Universidade Federal da Bahia (UFBA), Brazil \\ ${ }^{2}$ Integrated Institute of Health (SPORTCLIN), Salvador, Bahia, Brazil \\ ${ }^{3}$ Instituto Federal da Santa Catarina (IFSC), Brazil
}

Francisco José Gondim Pitanga ${ }^{1 *}$, Cristiano Penas Seara Pitanga ${ }^{2}$ and Carmem Cristina Beck ${ }^{3}$

* Corresponding author: Francisco José Gondim Pitanga, Faculty of Education, Departamento de Educação Física, Universidade Federal da Bahia (UFBA), Av. Rector Miguel Calmon, $s / n$ - Vale do Canela Salvador, Bahia, Brazil

\begin{abstract}
Purpose: To suggest the type and dose (duration and intensity) of physical activity more adequate to prevent abdominal fat in adults.

Methods: The evidences that were presented are part of studies on physical activity and abdominal fat published in the national and international literature.

Results: Physical activity (aerobic and resistance exercises), with a prolonged duration of moderate intensity for men and walking or moderate intensity for women, is suggested as the most adequate for the prevention/treatment of abdominal obesity.

Conclusions: For prevention/treatment of abdominal adiposity it is suggested prolonged physical activity (aerobics and resistance exercises) of walking or moderate intensity.
\end{abstract}

\section{Keywords}

Physical activity, Abdominal obesity, Prevention

\section{Introduction}

Abdominal obesity is defined as the amount of fat located in the abdomen region, mainly in the visceral region and has been used as an important predictor of metabolic and cardiovascular risk [1,2]. Different methods can be used to evaluate abdominal obesity, among them the conicity index and waist-hip ratio [3].

The mechanisms by which increased abdominal fat may influence the elevation of metabolic and cardiovascular risk may be partially explained by the excessive production of free fatty acids in the visceral abdominal region, which are distributed through the portal circulation exposing the liver to high concentrations of fat, reducing the hepatic removal of insulin, resulting in peripheral hyperinsulinemia, with the consequent increased risk of developing diabetes mellitus. Hyperinsulinemia may also cause disturbances in the concentrations of plasma lipids and high blood pressure [4] (Figure 1).

For some time, various studies have demonstrated that during physical activity lipid mobilization is more pronounced in visceral abdominal region than in subcutaneous abdominal area, as well as dose-response effect for reducing abdominal visceral fat due to the amount of physical activity [5-9].

Physical activity reduces visceral fat as a function of the lipolytic effect caused by the release of the catecholamines secreted during body movement, thus providing high rates of lipolysis in the abdominal region, mainly visceral [4]. With the reduction of the visceral fat, consequently, the levels of blood pressure, glycemia and plasma lipids are also diminished.

Thus, the main objective of this point of view is to suggest the type and quantity (duration and intensity) of physical activity more adequate to prevent abdominal fat in adults.

Scientific Evidence on Physical Activity and Abdominal Fat Produced in National and International Literature

The evidences that will be presented in this point of 


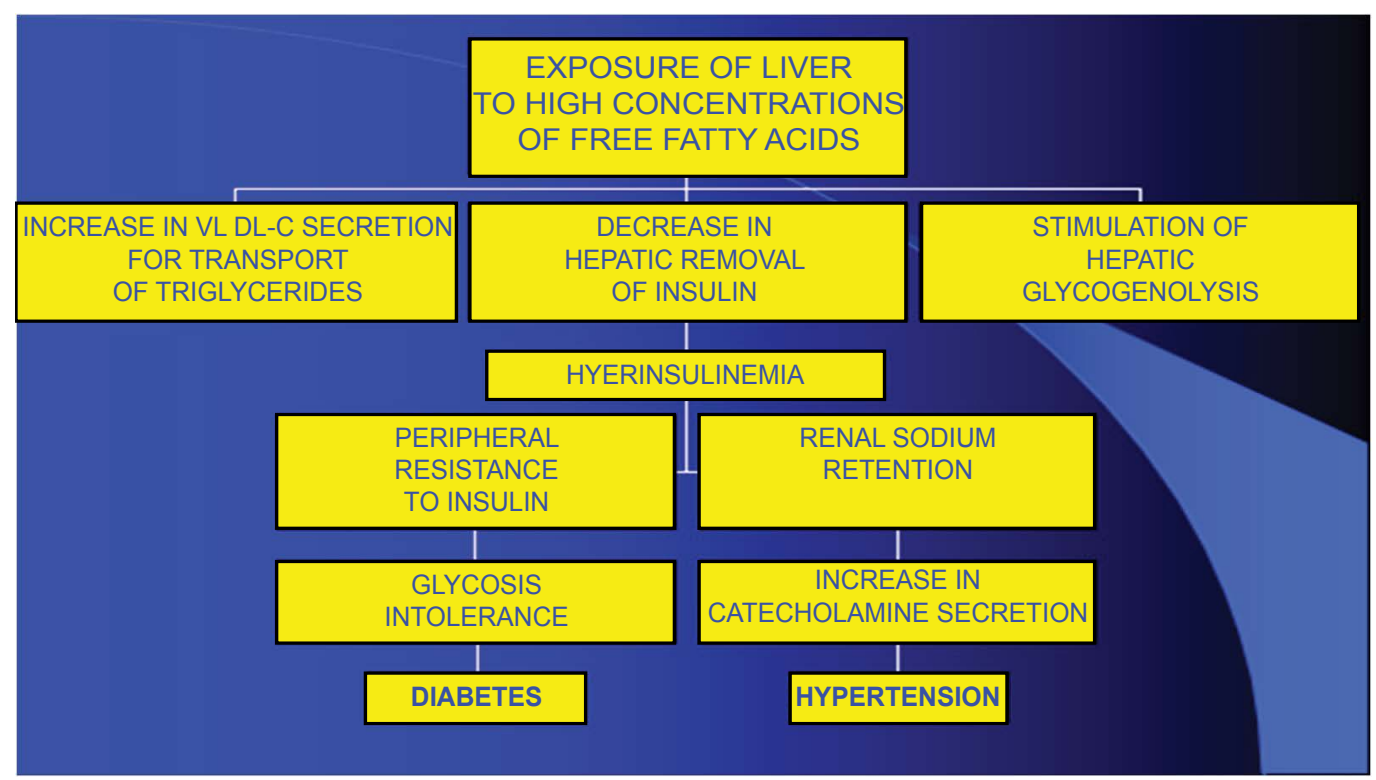

Figure 1: Mechanisms by which increased abdominal fat may influence the elevation of metabolic and cardiovascular risk.

view are part of studies on physical activity and abdominal fat published in the national and international literature that will be reported as follows:

The main studies on this topic demonstrate that physical activity (aerobic and resistance exercises) when performed with prolonged duration and walking or moderate intensity can provide very significant benefits in the prevention of abdominal obesity, besides also demonstrating that lipid mobilization during practice of physical exercise is more pronounced in the visceral abdominal region than in the subcutaneous region.

In one of the first published studies on exercise and abdominal fat, there were more significant reductions in the subcutaneous fat of the trunk than in the extremities in 13 male subjects submitted to 20 weeks of aerobic exercise on the ergometric bicycle indicating that the metabolism of the different fat deposits can react differently to the energy deficit induced by the exercise [5].

In the same perspective, Després, et al. [6] found that abdominal fat tissue, measured by computed tomography, was significantly reduced mainly in subcutaneous deposits in 13 women submitted to 14 months of aerobic training program. The same authors report that women are more resistant than men to reducing body fat, probably due to higher energy consumption and lower basal energy expenditure, as well as a lower peripheral lipolytic response of gluteofemoral adipose tissue, the main site of fat deposition in women. In addition, abdominal adipose tissue has a higher lipolytic response as a function of the effects of catecholamines that cause marked lipolysis in the abdominal tissue. For this reason, the mobilization of fat during physical exercises inducing reduction in body weight may be greater in the abdominal deposits than gluteofemoral [6].

Then, KOHRT, et al. [7] compared the distribution of body fat measured by thickness of skin folds between groups of sedentary and trained individuals of both sexes and verified lower values of fat in the central deposits of the trained group, indicating greater lipid mobilization in the abdominal, subscapular, suprailiac and chest regions [7].

Subsequently MOURIER, et al. [8] observed that physical exercise reduced visceral fat more significantly than subcutaneous fat measured by magnetic resonance imaging in the umbilical region in 24 non-insulin dependent diabetic patients submitted to 45 minutes of stationary bicycle three times per week, with a moderate intensity of $75 \%$ of maximal oxygen consumption, with intervention performed during two months. The same authors did not observe reductions in body weight of study participants during the intervention period [8].

A few years later, IRWIN, et al. [9] observed a significant dose-response effect for visceral fat reduction as a result of increased exercise duration in 86 postmenopausal women undergoing aerobic and resisted training lasting more than 195 minutes per week [9].

Subsequently, in publications of our research group, conducted in partnership with Portuguese researchers, it was observed that both physical activity in the form of walking and moderate intensity, lasting approximately 400 minutes per week, discriminated and was associated with a reduction in visceral fat in Portuguese postmenopausal women $[10,11]$ (Figure 2).

More recently in a study published with data from 1249 participants of the Framingham Third Generation and Omni II cohorts it was demonstrated that Moderate-to-Vigorous Physical Activity (MVPA) measured with accelerometry was associated with decreased Visceral Adipose Tissue (VAT) measured by CT computerized. For every 30 minute/day increase in MVPA there were significant reductions in VAT for both men and women [12]. 


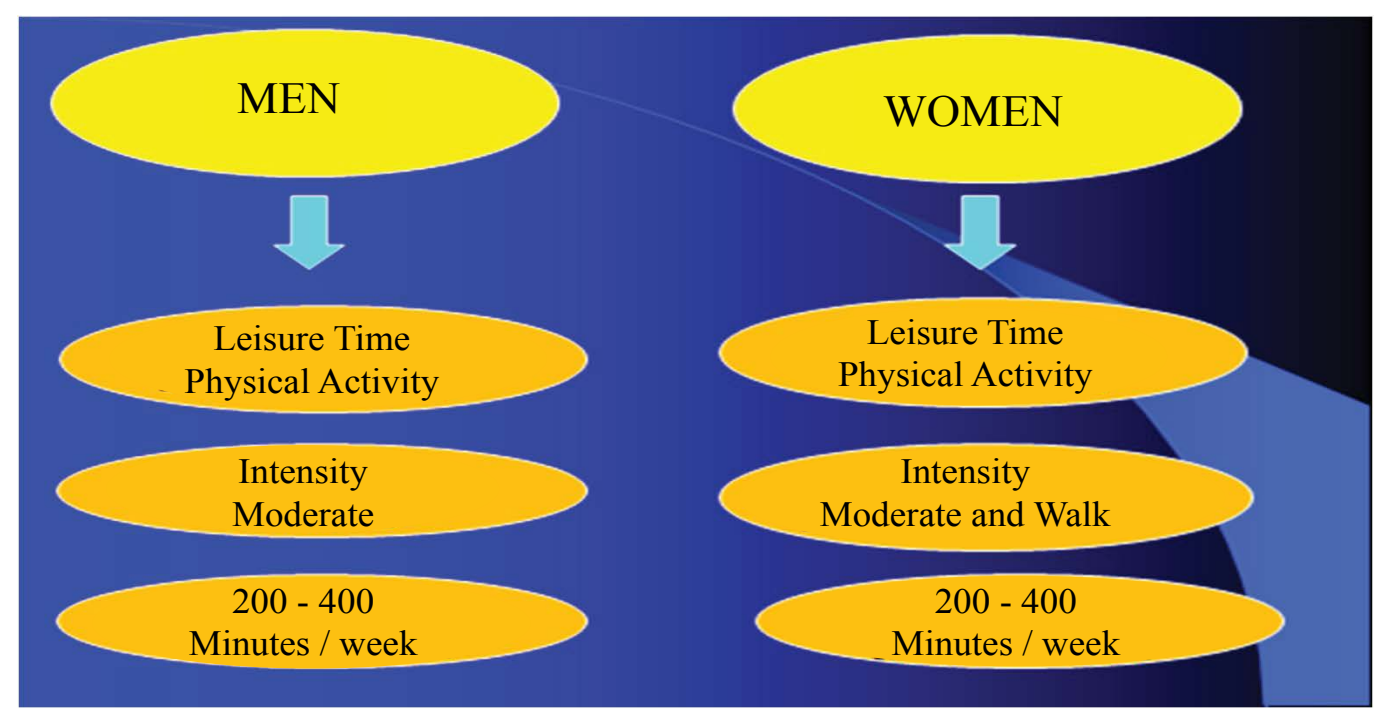

Figure 2: Physical activity in the prevention of abdominal obesity in adults of both sexes.

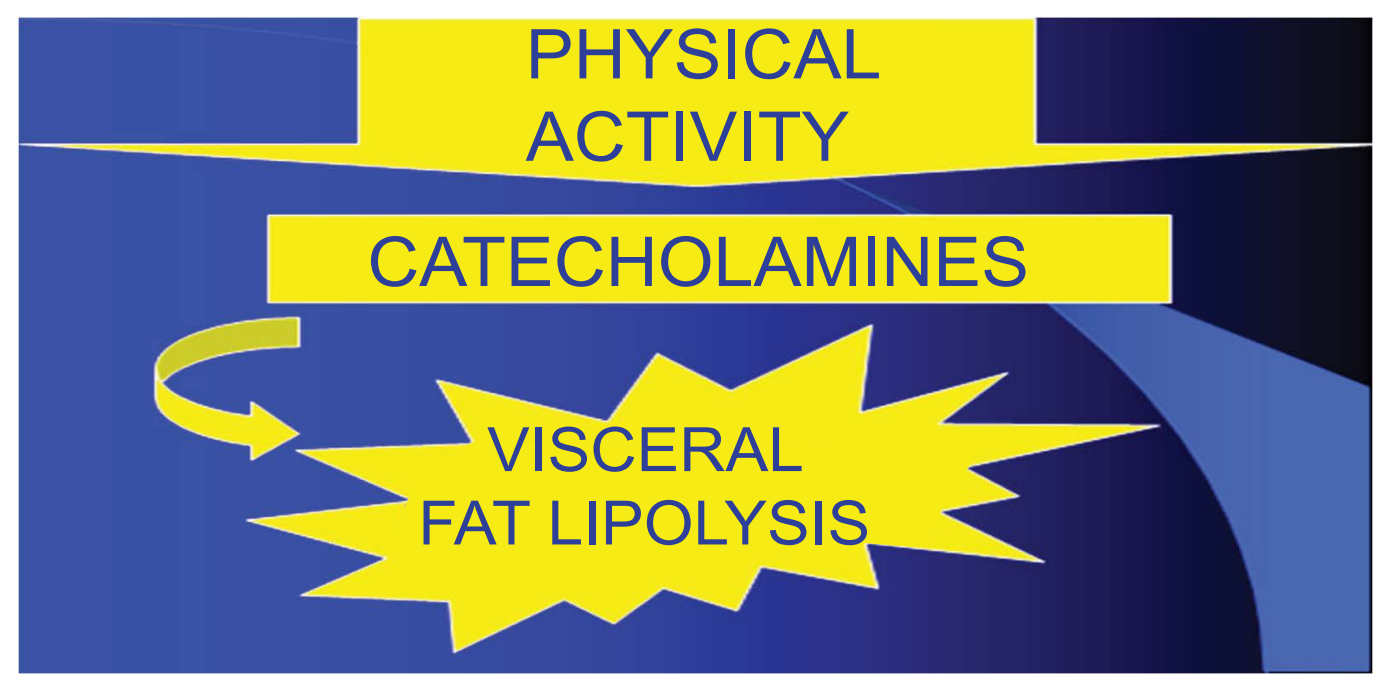

Figure 3: Lipolytic effect of catecholamines released during physical activity.

Table 1: Recommendations for physical activity in the prevention of abdominal obesity in adults of both sexes.

\begin{tabular}{|l|l|l|}
\hline Physical activity & Men & Women \\
\hline Type & $\begin{array}{l}\text { Leisure Time Physical Activity (Sports, Fights, } \\
\text { Dances, Gymnastics, Running, Bike, Resisted } \\
\text { Training, among others) }\end{array}$ & $\begin{array}{l}\text { Leisure Time Physical Activity (Sports, Fights, } \\
\text { Dances, Gymnastics, Running, Bike, Resisted } \\
\text { Duration }\end{array}$ \\
\hline Intensity & 200 to 400 minutes per week & Training, among others) \\
\hline
\end{tabular}

These results may be partly explained by the fact that the main mechanism that would lead to the reduction of visceral fat would be the lipolytic effect of the catecholamines released during physical activity that would cause greater use of the abdominal fatty acids as an energetic substrate, that is, would cause high rates of lipolysis in the abdominal visceral region, which would be maximized as a function of the amount of physical activity [4] (Figure 3).

\section{Final Considerations}

Thus, based on the results of the studies cited above it is suggested prolonged physical activity (aerobics and resistance exercises) of moderate intensity for men and walking or moderate intensity, also of prolonged dura- tion, for women, as the most suitable for prevention/ treatment of abdominal adiposity (Table 1 ).

We also suggest longitudinal studies on the amount of physical activity necessary to prevent abdominal fat in adults to confirm the evidence observed in the studies analyzed in this point of view.

\section{References}

1. Kotronen A, Yki-Järvinen $H$, Sevastianova $K$, Bergholm R, Hakkarainen A, et al. (2011) Comparison of the relative contributions of intra-abdominal and liver fat to components of the metabolic syndrome. Obesity (Silver Spring) 19: 23-28.

2. Seo JA, Kim BG, Cho H, Kim HS, Park J, et al. (2009) The cutoff values of visceral fat area and waist circumference for identifying subjects at risk for metabolic syndrome in elderly 
Korean: Ansan Geriatric (AGE) cohort study. BMC Public Health 2: 443-449.

3. Pitanga FJG (2011) Antropometria na avaliação da obesidade abdominal e risco coronariano. Rev Bras Cineantropom Desempenho Hum 13: 238-241.

4. Björntorp $P$ (1991) Adipose tissue distribution and function. Int J Obes 15: 67-81.

5. Després JP, Bouchard C, Tremblay A, Savard R, Marcotte $M$ (1985) Effects of aerobic training on fat distribution in male subjects. Med Sci Sports Exerc 17: 113-118.

6. Després JP, Pouliot MC, Moorjani S, Nadeau A, Tremblay A, et al. (1991) Loss of abdominal fat and metabolic response to exercise training in obese women. Am J Physiol 261: 159-167.

7. Kohrt WM, Malley MT, Dalsky GP, Holloszy JO (1992) Body composition of healthy sedentary and trained, young and older men and women. Med Sci Sports Exerc 24: 832-837.

8. Mourier A, Gautier JF, De Kerviler E, Bigard AX, Villette JM, et al. (1997) Mobilization of visceral adipose tissuerelated to the improvement in insulin sensitivity in response to physical training in NIDDM. Effects of branched-chain amino acid supplements. Diabetes Care 20: 385-391.

9. Irwin ML, Yasui Y, Ulrich CM, Bowen D, Rudolph RE, et al. (2003) Effect of exercise on total and intra-abdominal body fat in postmenopausal women: a randomized controlled trial. JAMA 289: 323-330.

10. Pitanga CP, Pitanga FJ, Beck CC, Gabriel RE, Moreira MH (2012) [Level of physical activity in the prevention of excess visceral fat in postmenopausal women: how much is needed?]. Arq Bras Endocrinol Metabol 56: 358-363.

11. Pitanga CPS, Pitanga FJG, Moreira MHR, Gabriel REC (2014) Associação entre o nível de atividade física e a área de gordura visceral em mulheres pós-menopáusicas. Rev Bras Med Esporte 20: 252-256.

12. Murabito JM, Pedley A, Massaro JM, Vasan RS, Esliger D, et al. (2015) Moderate-to-vigorous physical activity with accelerometry is associated with visceral adipose tissue in adults. J Am Heart Assoc 4: 1379. 